\title{
Variation in cattle liveweights at marketing
}

\author{
R.W. WEBBY, A.B. PLEASANTS and L.A. GREAVES \\ AgResearch, Whatawhata Research Centre, Private Bag 3089, Hamilton, New Zealand
}

\section{Abstract}

The liveweights of Friesian bulls farmed on 3 farmlets during 4 years were analysed to find how the variation in liveweight increased through time, and to review some possible farm management strategies for limiting the increase in this variation. There were 59 bulls in 1986, 66 bulls in 1987, 59 bulls in 1988 and 61 bulls in 1989. The variation in animal liveweights within a mob increased linearly through time. The small variance in the slopes of the estimates indicated that the increase in liveweight variation through time could be predicted very accurately. The rate of increase of variation through time differed in only one year (1987; $\mathrm{P}<0.01)$. Variation in animal liveweight between farmlets was constant through time, and not associated with the rate of increase of within mob liveweight variation. It was shown that the ranking of animals within the frequency distribution of animal liveweight changed through time. Thus the current liveweight rank of an animal was no guide to liveweight rank 5 or 6 months in the future. This suggests that minimising the increase in liveweight variation through time by dividing a mob of cattle is not feasible. The importance of control of variation in agricultural products for the operation of on-farm quality assurance schemes is discussed, and avenues for exploration of management tactics designed to minimise variation in the production of animals for slaughter suggested.

K eywords: bulls, liveweight, marketing, on-farm quality assurance

\section{Introduction}

A mob of cattle will have a range of liveweights at any given time despite any effort to try to produce uniformity in liveweight or any other production trait. Conspicuous variation is a characteristic of biological systems, and a factor with which all farmers will be familiar.

Variation in a mob of cattle means that some animals will be ready for slaughter before others. Historically, management of this variation has not been a large problem for farmers. Typically, animals are marketed as they became ready for slaughter, and animals not ready for slaughter are retained until they are judged to be ready. Thus a farmer trades variation in animal liveweight for variation in time of slaughter. Such a marketing strategy defines commodity trading, a business that has typified New Zealand agriculture in the past and become the basis of many of the problems we face on world markets.

In the future farmers need to change from commodity trading of a product to trading of products based on quality. The concept of quality in a product has been poorly defined, most people associating the concept with some subjective personal standard. However, an objective definition is possible - indeed essential - and it is based on the concept of fitness for use (Purchas 1993). This concept defines variation in the product to be the principal reason why a product may fail the expectations of the customer who wishes to use the product.

A product is 'fit for use', and a quality product, if it performs within specifications previously laid down by a customer. Emphasising that the performance range must stay within specification tolerance limits defines product quality in terms of the variation in the product. The process of continual improvement in quality, noted as essential for access to the Japanese market by Forgie (1993), represents the application of knowledge and technology towards performance within narrower tolerances.

The immediate customer of a farmer is a meat processor. The meat processor wants product from the farmer which is 'fit for use'. That is, carcasses of a uniform weight delivered at an agreed time. This in turn enables the meat processor to satisfy their customers.

Contracts between a farmer and a meat processor for the farmer to deliver animals for slaughter at a given time, and of an agreed carcass weight are the practical implications of quality trading. But such contract requirements mean that the most useful management tool a farmer has for controlling variation, that of time, is no longer available. Furthermore, contract specifications require that variation in slaughter animals be controlled or else penalties could be incurred as a result of failing the contract.

The future adoption of quality assurance, in the guise of contracts to supply stock to time and carcass specifications, will demand that the influence of various factors on variation be appraised. This paper reports 
observations on the way variation in liveweight in mobs of cattle changes over time, and investigates the possibility of strategies to minimise variation in this trait.

\section{Materials and methods}

\section{Experimental}

The monthly liveweights of Friesian bulls randomly allocated to 3 farmlets in each of 4 years in trials described by Sheath et al. (1990) and Webby et al. (1990) were used. Bulls were approximately 4 months of age when they entered the trial at the end of November in each year. The trial finished in February, 15 months later.

Bull calves were reared under contract from Friesian dairy herds using high BI Friesian sires. Calves were supplied on 1 November each year at an average age of $12 \pm 2$ weeks. Calves were grazed together as one mob adjacent to the experimental farmlets before entering the trial at the end of November.

Bulls were grazed with ewes in each farmlet on a sheep:cattle ratio of 70:30. Bulls were the priority animals grazing ahead of the ewes through most of the year. When lambing began bulls were allocated their own block for grazing until the lambs were weaned. From lamb weaning until February the bulls were grazed ahead of, with, or behind the lambs. The ewes followed the bulls.

Liveweight measurements were taken after standardising the animals for gut fill. This was achieved by running the bulls on pastures with more than $6 \mathrm{~cm}$ of leaf for 18 hours before weighing. Animals were all weighed within one hour of leaving the pasture.

\section{Describing variation}

The variation in a population (such as a mob of cattle) is described by a figure known as the standard deviation. The standard deviation measures the spread of the variable (e.g., animal liveweight) about the population mean. As the variation in the population increases so does the size of the standard deviation. Generally about two thirds of the population will lie between the mean minus the standard deviation and the mean plus the standard deviation (exactly if the population is normally distributed). The details of the calculation of the standard deviation can be found in any book on statistics, e.g., Snedecor \& Cochran (1967).

\section{Statisticalanalysis}

Each year of the trial was analysed separately. Within year, the animals were classified by farmlet. In the analysis farmlet was considered a random factor, and analysed by a type II analysis of variance.
To assess changes in the relative ranking over time of bulls within a herd logit analysis (Wonnacott \& Wonnacott 1979) was used. This analysis estimated the odds that an animal would be in a group of heavier bulls at a future time given the within-herd liveweight ranking at some past time. To try to minimise the influence of gut fill on animal liveweight differences the group of heavy animals was defined as those animals in excess of $5 \mathrm{~kg}$ of the herd mean liveweight.

\section{Results}

The numbers of bulls and liveweight results are shown in Table 1.

The standard deviation of liveweight for bulls within farmlets increased linearly, while the standard deviation of liveweight for bulls between farmlets remained constant (Figures 1-4). This means that the increase in the variation of liveweight over time, measured by the standard deviation, was an attribute of factors within a mob, and not the result of the different environments provided by the different farmlets

There was no relationship between the rate of increase of variation in animal liveweight and the growth rate of the bulls (Tables 1 and 2).

There was no evidence that the increase in the variation of liveweight through time was associated with a constant coefficient of variation.

Table 1 Number of bulls, average initial liveweight, and average final liveweight for each year.

\begin{tabular}{|c|c|c|c|}
\hline Year & Number of Bulls & $\begin{array}{l}\text { Average Initial } \\
\text { Liveweight in } \\
\text { November }(\mathrm{kg})\end{array}$ & $\begin{array}{l}\text { Average Final } \\
\text { Liveweight in } \\
\text { December ( } \mathrm{kg})\end{array}$ \\
\hline $\begin{array}{r}1986 \\
1987\end{array}$ & $\begin{array}{l}59 \\
68\end{array}$ & 102 & $\begin{array}{l}391 \\
445\end{array}$ \\
\hline 1988 & 59 & 118 & 409 \\
\hline 1969 & 61 & 115 & 456 \\
\hline
\end{tabular}

Table2 The intercept $(\mathrm{kg})$ and slope $(\mathrm{kg}$ per day) of the regression of the standard deviation of liveweight on time, and the standard deviation of the final liveweight $\mathbf{( k g )}$ for each year

\begin{tabular}{cccc}
\hline Year & $\begin{array}{c}\text { Intercept } \\
(\mathrm{kg})\end{array}$ & $\begin{array}{c}\text { Slope } \\
\text { (kg per day) }\end{array}$ & $\begin{array}{c}\text { Standard } \\
\text { Deviation of } \\
\text { Final } \\
\text { Liveweight }(\mathrm{kg})\end{array}$ \\
\hline 1986 & $13.70^{\prime} \pm 0.188$ & $0.059^{4} \pm 0.005$ & 38.1 \\
1907 & $12.00^{\prime} \pm 0.056$ & $0.040^{3} \pm 0.002$ & 29.2 \\
1988 & $5.54^{2} \pm 0.661$ & $0.061^{\prime} \pm 0.003$ & 33.2 \\
1989 & $6.74^{\prime} \pm 0.505$ & $0.0534 \pm 0.002$ & 30.0 \\
\hline
\end{tabular}

Variables with different superscripts within intercept and slope are significantly different $(P<0.01)$. 
Figure 1 Standard deviation of bull liveweight, 1986.

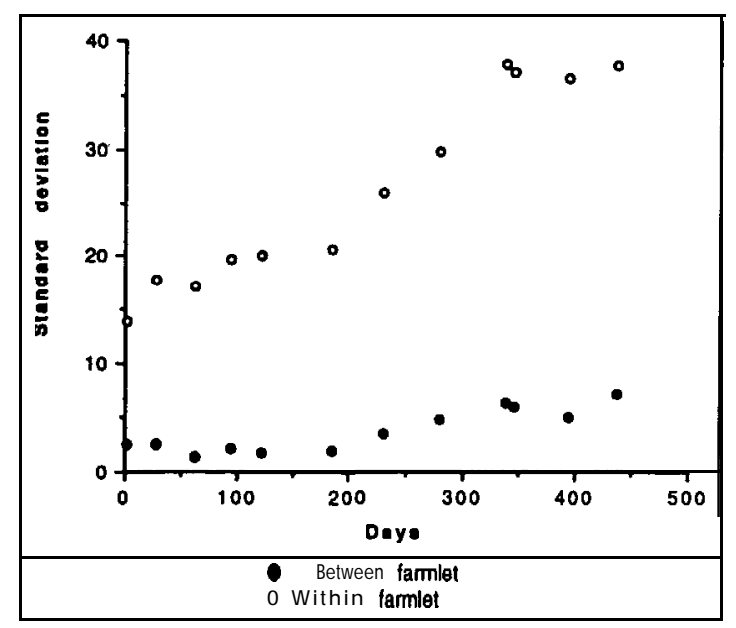

Figure 3 Standard deviation of bull liveweight, 1988.

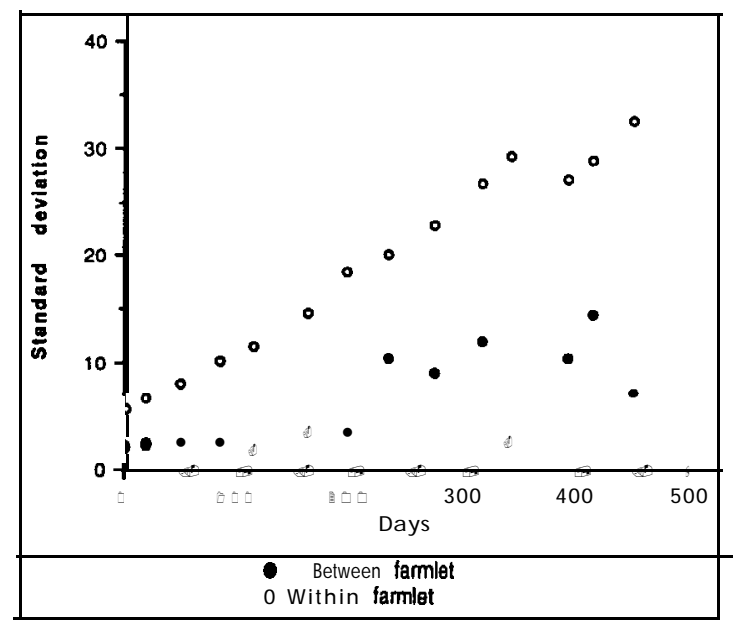

The between-farmlet standard deviation changed according to the year. This is to be expected as differences in aspect, soil type, etc., interact with climatic effects.

The standard deviations for the beginning liveweight for 1986 and 1987 were significantly $(\mathbf{P}<0.01)$ greater than the standard deviations for the beginning liveweight in 1988 and 1989 (Table 2). However, only the slope for the year 1987 is significantly different $(\mathrm{P}<0.01)$ from the slopes of the other years. The standard deviation of the final liveweights was not related to the standard deviation of the initial liveweights.

The small standard error for the slopes of the regressions of the standard deviation of liveweight on time (Table 2) suggest that predictions of the standard
Figure 2 Standard deviation of bull liveweight, 1987.

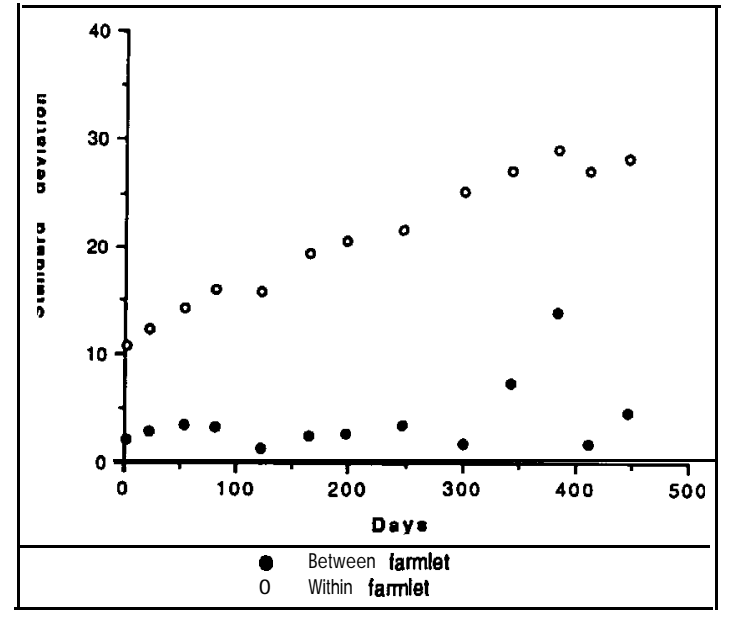

Figure 4 Standard deviation of bull liveweight, 1989.

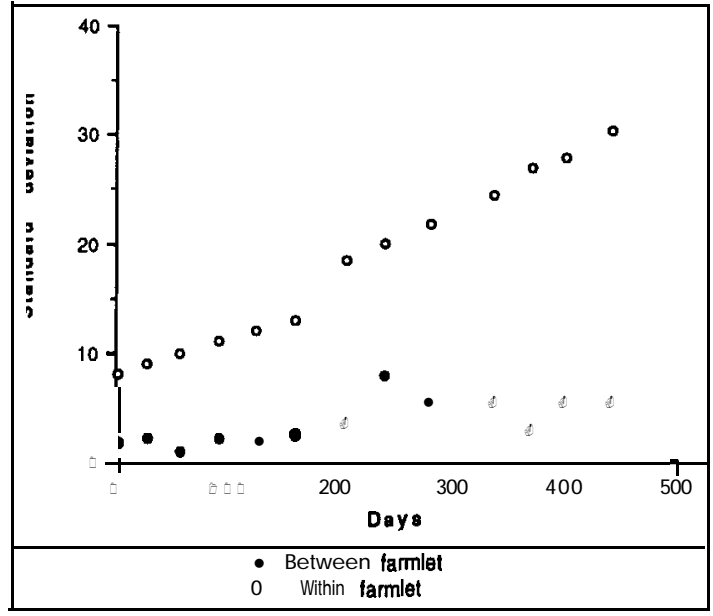

deviations of animal liveweight in the future, given current information on the increase in liveweight standard deviation through time, give accurate information over the range of liveweights represented in these trials.

Regression of the final liveweight on intermediate liveweights indicated that while bulls that were heavier at intermediate liveweights were expected to be heavier at final liveweights, the errors of prediction were very high. Thus the relative ranking of animals within a herd tended to change through time, the particular liveweight ranking of a bull within the herd now being a poor guide to future liveweight ranking in the herd. It was considered that this was most likely due to variation in gut fill among the animals. 
Summarising the information on bull liveweight and liveweight gain during the first year of each trial by principal components showed that $97 \%$ of the variance of these variables was accounted for by the first principal component. Using this first principal component as the independent variable in a regression on final liveweight failed to improve the predictability of final liveweight. This suggests that there is no information in the pattern of growth of the bulls in their first year which could be used to improve the prediction of the final within-herd liveweight ranking.

Figure 5 Odds ratio for final liveweight ranking in December 1986 given the liveweight rankings in December 1985 and August 1986.

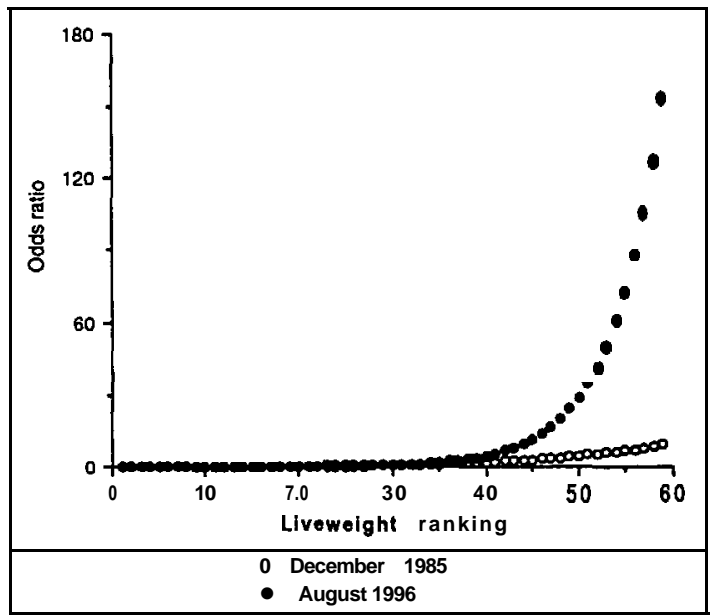

Figure 7 Odds ratio for final liveweight ranking in December 1988 given the liveweight rankings in December 1987 and August 1988.

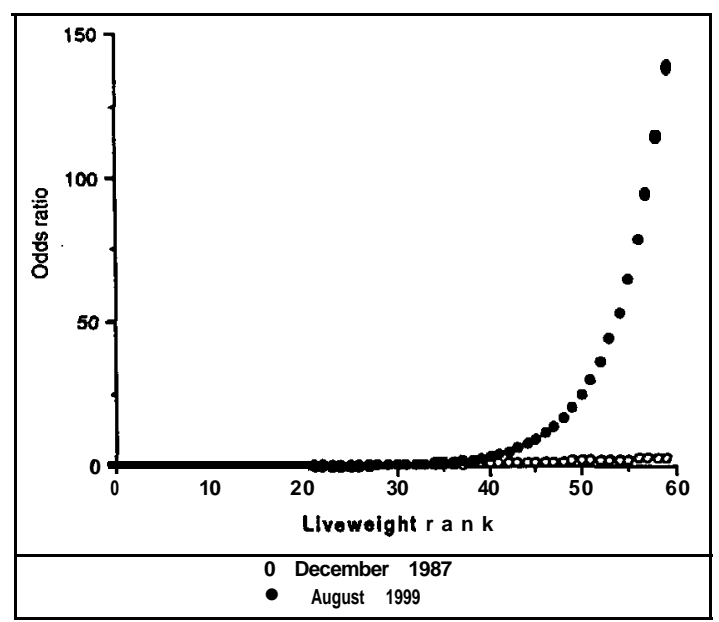

Figures 5-8 show that the ranking of bulls in the August liveweight 6 months from final liveweight provided good evidence that bulls ranked in the top $30 \%$ of liveweights will be in the top group for final liveweight. As animal ranking fell below this figure the chance that a bull would be in the top group for final liveweight, as measured by the odds ratio, fell to the point where no useful prediction could be made.

For bulls ranked in December, 1 year before final liveweight, the chances of being able to identify a subgroup of useful size of bulls which will be in the top group for final liveweight was very low.

Figure 6 Odds ratio for final liveweight ranking in December 1987 given the liveweight rankings in December 1986 and August 1987.

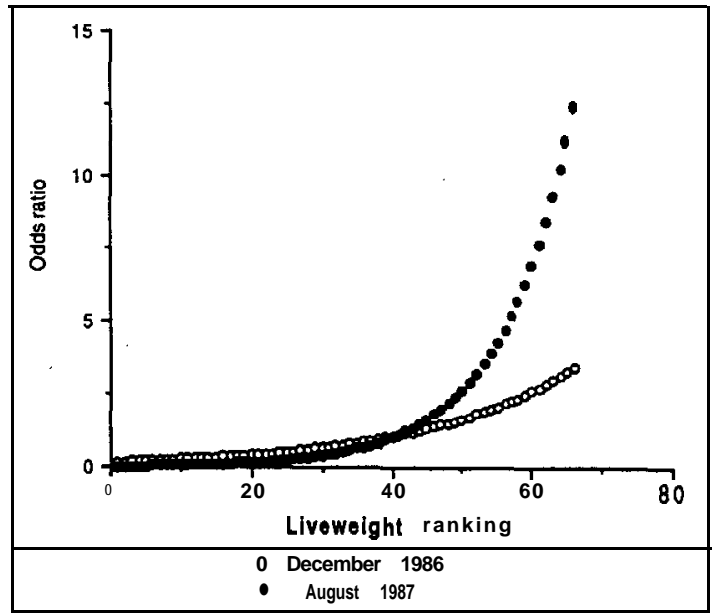

Figure 8 Odds ratio for final liveweight ranking in December 1989 given the liveweight makings in December 1988 and August 1989.

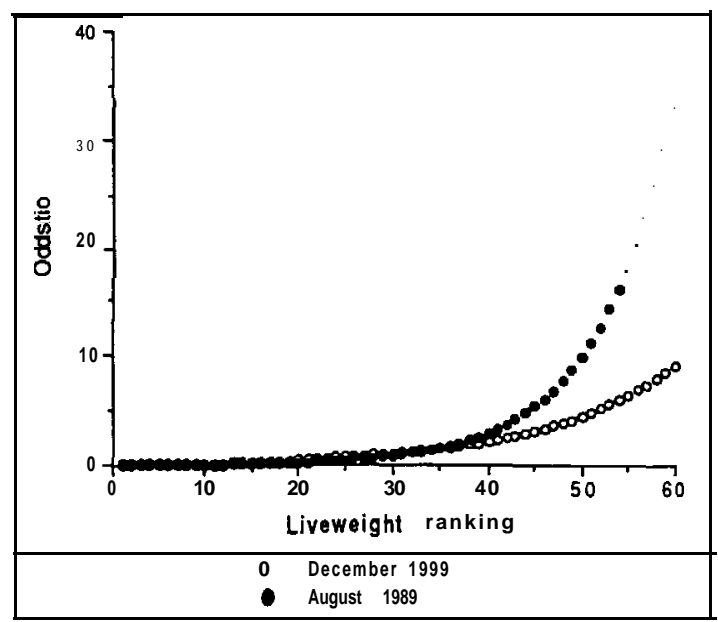




\section{Discussion}

The animals measured in the trials reported in this paper represent a small sample from a limited range of conditions. However, three conclusions can be drawn from this analysis

- Within a year the farmlets were managed to be as similar as possible. Since the between-farmlet standard deviation did not increase over time this testifies to the success of this strategy, and suggests that management of variation in animal liveweight due to environmental effects is possible.

- Within a mob of cattle the standard deviation of liveweight increases linearly with time. Thus when sufficient measurements have been made to fix the increase of the standard deviation with time a useful prediction of the spread of cattle weights in the future can be made.

- The relative ranking of cattle within a mob changes over time. The relative ranking could not be predicted from on early information of animal liveweight and growth path.

Identification of animals expected to form the upper quautiles of the liveweight distribution in the herd 6 months in the future can be done with confidence for only the top $30 \%$ of the animals. Identification of the top animals in a herd 1 year in the future based on information about their relative ranking and growth rates appears to be unpredictable. This suggests a large gap in the understanding of the way cattle grow, a lack of knowledge that will need to be addressed if goals of controlling variation on a farm, necessary to qualify for IS0 9000 certification, are to be achieved.

This analysis shows that there are differences between years in the rate at which the variation increases within a mob. Sex, mob size, breed, compensatory growth, rotational grazing verses set stocking are other factors which may have an influence. While this analysis suggests that some management strategies to minimise variation, such as splitting mobs based on one liveweight, may not be effective, further work is needed. One explanation of the failure to predict the relative ranking of animal liveweight is that animals do not grow steadily, but change their rate of growth rapidly in response to physiological mechanisms. A careful examination of the way individual bulls in a farm grazing system grow might assist in explaining these observations.

Research workers and farmers have generally made decisions about production based on the way different factors influence means. It was not important to consider how these factors might also influence the variation. In the new era of quality assurance the management of variation on a farm becomes much more central. We hope that this paper will assist in alerting farmers and their advisors to these issues.

\section{ACKNOWLEDGEMENTS}

G.W. Sheath and D.G. McCall for assistance in the preparation of this paper.

\section{REFERENCES}

Forgie, R. 1993. A meat company approach to the north asia market. Proceedings of the 1993 Central Districts Sheep and Beef Cattle Conference 2: 105110.

Purchas, R. 1993. Definition and objective measurement of quality beef. Proceedings of the 1993 Central Districts Sheep and Beef Cattle Conference 2: 101104.

Sheath, G.W.; Webby, R.W.; Pengelly, W.J.; Boom, C.J. 1990. Finishing lambs in hill country. Proceedings of the New Zealand Grassland Association 51: 181-186.

Snedecor, G.W.; Cochran, W.G. 1967. Statistical methods. 6th Edition. Iowa, Iowa State University Press.

Webby, R.W.; Sheath, G.W.; Boom, C.J. 1990. The performance of new pasture cultivars in hill country finishing systems. Proceedings of the New Zealand Grasslands Association 51: 15 1-1 56.

Wonnacott, R.J.; Wonnacott, T.H. 1979. Econometrics. 2nd Edition. New York, John Wiley \& Sons. 